\title{
Lessons Learned in Managing Patients with Colorectal Cancer During the COVID-19 Pandemic
}

Reetu Mukherii, $M D^{1} \odot$

John L. Marshall, $M D^{1,2, *}$

\author{
Address \\ ${ }^{1}$ Department of Hematology and Oncology, Georgetown University Medical Center, \\ Washington, DC, 20057, USA \\ ${ }^{*}, 2$ Ruesch Center for the Cure of Gastrointestinal Cancers, Lombardi \\ Comprehensive Cancer Center, Georgetown University Medical Center, \\ 3800 Reservoir Road, Washington, DC, 20057, USA \\ Email: marshalj@georgetown.edu
}

Published online: 23 August 2021

(C) The Author(s), under exclusive licence to Springer Science+Business Media, LLC, part of Springer Nature 2021

This article is part of the Topical Collection on Lower Gastrointestinal Cancers

Keywords Colorectal cancer · COVID-19 • Coronavirus · Pandemic · Cancer · Colon cancer · Rectal cancer · Malignancy

\section{Opinion statement}

The COVID-19 pandemic forced us to rapidly and dramatically shift our medical priorities and decision making. With little literature or experience to rely on, the initial priority was to minimize patient exposure to the hospital and to others. It remains unclear whether cancer patients are at higher risk of infection or serious complications, or if it is our traditional therapies that place them to be at higher risk. By far, the greatest negative impact was on screening. Routine colonoscopies were considered elective, and as a result, delays in diagnosis will be felt for years to come. The most positive changes were the incorporation of tele-visits, increased use of oral therapies, alterations in treatment schedules of both chemotherapy and radiation, and an increased emphasis on neoadjuvant therapy. These too will be felt for years to come. The colorectal cancer medical community has responded collaboratively and effectively to maintain treatment and to optimize outcomes for our patients during the COVID-19 pandemic.

\section{Introduction}

The pandemic of coronavirus disease 2019 (COVID19), a disease caused by the novel human coronavirus severe acute respiratory syndrome coronavirus 2 (SARS-
CoV-2), led to signification changes in healthcare infrastructure and challenges in cancer care starting in late 2019. COVID-19-infected patients can present 
asymptomatically to critically ill, and the infection is associated with high intubation rates and in-hospital mortality $[1,2]$. The dominant route of transmission is respiratory with reports of variable infectivity rates ranging from 17 to $62 \%$ and an estimated one-half of cases transmitted from asymptomatic individuals [3-8]. As the first wave of COVID-19 cases overwhelmed medical systems across the world, many hospitals scrambled to redistribute medical providers to care for COVID-19 patients, stopped non-emergency surgical procedures, functioned at reduced capacity, and adopted new systems to limit patient gatherings and exposures.

In the USA, colorectal cancer (CRC) is the third most commonly diagnosed cancer in men and women with an estimated 147,950 new cases diagnosed in 2020 [9]. While the majority of newly diagnosed CRCs is locoregional and associated 5-year survival rates of 71$90 \%$, about $22 \%$ of new cases are metastatic at diagnosis and associated with significant mortality (5-year survival rate of $14.3 \%)$. Unfortunately, the pandemic led to marked reductions in elective colonoscopies, a screening modality known to significantly reduce CRC-related mortality [10]. The pandemic also forced cancer patients and medical providers to urgently balance the risks of potential COVID-19 exposures, morbidity, and mortality with the non-elective treatments for cancers.

As of April 4, 2021, the cumulative global COVID-19 cases exceeded 130 million with over two million attributable deaths since the beginning of the pandemic [11]. Over four million new cases are still diagnosed weekly. While the pandemic landscape is evolving with novel treatments and most recently vaccination distribution, we must continue to advocate for our cancer patients and balance the risks and benefits of CRC interventions. Here, we review what we have learned so far in managing CRC patients based on published studies and reflect upon our personal experiences during these unprecedented pandemic times.

\section{COVID-19 and risks in cancer patients}

The immunosuppressive nature of cancer, myelosuppressive therapies, older demographic, and frequent medical facility exposures raise concerns for COVID-19 infections in the cancer population. A few large studies suggest that cancer patients have higher risks of complications and death from COVID-19 infection. In May 2020, the COVID-19 and Cancer Consortium (CCC-19) published results from a retrospective cohort study of 928 USA and UK patients diagnosed with COVID-19 across many cancer subtypes [12]. The mortality rate within 30 days of COVID-19 diagnoses was 13\%, and $26 \%$ of patients met a secondary composite endpoint of severe illness including death, hospital or ICU admission, mechanical ventilation, or a combination of these. Post-hoc analyses revealed that older age, race, number of co-morbidities, hematologic malignancy, Eastern Cooperative Oncology Group performance status of two or higher, treatment with azithromycin and/or hydroxychloroquine, and progressive or unknown cancer status were associated with increased rates of secondary composite endpoints. The UK Coronavirus Cancer Monitoring Project's (UKCCMP) prospective observational study of 800 UK cancer patients reported a $28 \%$ mortality rate with age and comorbidities (hypertension and cardiovascular disease) being significantly associated with mortality [13]. A systematic review and pooled analysis of over 18,650 cancer patients with COVID-19 from 52 international studies reported a $25.6 \%$ mortality rate $[14 \bullet]$. Other individual and pooled studies report mortality rates between 12 and 30\% and suggest that a cancer diagnosis is associated with worse COVID-19 outcomes [15-21]. In contrast, some studies report more comparable outcomes between cancer and non-cancer patients $[22,23]$. 
The effect of cancer therapy on COVID-19 outcomes is still being described. In patients with solid tumors in the CCC-19 study, subgroup analyses did not suggest associations between active cytotoxic therapy, non-cytotoxic therapy, or recent surgery and clinical outcomes although these were descriptive results with no statistical analyses. In the UKCCMP study, after adjusting for age, gender, and comorbidities, cancer-related therapy (chemotherapy, immunotherapy, targeted therapy, hormonal therapy, and radiotherapy) in the 4 weeks prior to COVID-19 diagnosis had no significant effect on mortality [13]. A study of 585 patients in New York City, USA, reported similar outcomes in cancer versus non-cancer patients, and $45 \%$ of the cancer patients had received immunosuppressive therapy within 90 days of hospital admission [23]. Other centers have also reported low rates of COVID-19 infection while on systemic therapy [24]. In contrast, some studies suggest that mortality is higher in patients having received active cancer treatment $[17,25,26]$. A large case-control study including over 73 million electronic medical records reported patients with cancer had significantly higher risks of COVID-19 infection and worse outcomes [21]. Conflicting results in mortality may be due to variations in the underlying characteristics of cancer patients across studies. While the identification of factors and patient subgroups continue to evolve, the US Center for Disease Control (CDC) has included cancer as a condition portending high risks of severe COVID-19 illness, and in clinical practice, these patients require special considerations in aggressiveness of cancer management while mitigating their infectious risks [27].

It is important to recognize cancer patients comprise a heterogenous group with different ages, comorbidities, risk factors, treatment strategies, stages of progression, and prognoses. Few studies suggest that hematologic and lung cancer subtypes are associated with higher COVID-19 risks [12, 20, 26, 28]. There are limited data specifically related to CRC and COVID-19. Lee et al. studied COVID-19 risks across multiple cancers and also reported that patients with leukemia had statistically significant increased COVID-19-related fatality, but such findings were not found in CRC patients where the case-fatality rate was 0.282 (OR $0.85,95 \%$ CI $0.44-1.64, \mathrm{p}=0.63$ ) [29]. Tuechh et al. reported no increased COVID-19-related mortality in CRC patients having recently undergone surgical resection [30]. Further studies with larger populations of CRC patients are required to better characterize the outcomes of COVID-19 patients in this group.

\section{Screening and impact on early-stage colorectal cancer}

Starting March 2020, many healthcare systems mandated delaying nonemergent screening and diagnostic endoscopies due to personal protective equipment (PPE), operating room, and staff constraints. In addition, endoscopies are aerosolizing procedures conferring high COVID-19 transmission risk [31]. However, colonoscopies are also crucial in early CRC prevention and considerably reduce CRC incidence and mortality by over $60 \%$ in populations through removal of precancerous adenomas [10, 32].

A study across four population-based National Health Service (NHS) datasets in England revealed a 63\% relative reduction in colonoscopy referrals and $92 \%$ relative reduction in number of colonoscopies performed after the 
first lockdown in April 2020 compared to 2019 levels [33]. Another UK study reported colonoscopy activity dropped to a nadir of 5\% relative to pre-COVID19 activity and was associated with a $58 \%$ reduction in weekly cancer diagnoses [34]. In March 2020, the US Surgeon General and US Centers for Medicare and Medicaid Service issued guidance to delay non-urgent procedures. Consequently, a USA study similarly noted a reduction of about $50 \%$ in newly identified CRC cases towards the end of March and into April 2020 compared to preCOVID-19 times [35]. The Veterans Affairs Health System, one of the largest integrated health systems in the USA, reported a striking 78\% decrease in upper endoscopies and 93\% decrease in colonoscopies performed in April 2020

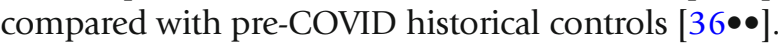

Mandated colonoscopy cancelations and delays raise concerns about missing early CRC diagnoses in populations. Estimation models suggest delays in colonoscopy screening up to 12 months after a positive fecal immunochemical test (FIT) result in loss of screening benefit, and early prediction models in response to COVID-19 suggest a 6-month delay would result in stage I to II progression in $3 \%$ of patients $[37,38]$. Other prediction models estimate an excess of over 4000 CRC deaths over the next 10 years due to the pandemic impacts on screening [39]. The University of Pennsylvania, USA, already reported a $45 \%$ decrease in new gastrointestinal (GI) malignancy visits with the highest decrease of 53\% in new CRC cases likely attributed to the $91 \%$ drop in colonoscopies performed during the pandemic [40].

Alternative methods such as non-invasive, at-home FIT testing and implementation of outreach programs were recommended in place of invasive colonoscopies for screening and to prioritize patients for colonoscopies [41]. However, the increase in non-invasive screening measures did not compensate for the overall decrease in all screening modalities at some institutions [42]. The actual clinical repercussions of alternative screenings, outreach programs, and delayed colonoscopy screenings especially in underserved populations may not be known for some time. Continued optimization of peri-procedural safety and screening methods is crucial for early CRC diagnosis and reducing mortality.

The anticipated pandemic effects across socioeconomic and geographic groups that historically experienced disparities in CRC outcomes are especially concerning. African Americans, especially men, carry the highest incidence and mortality rate of CRC across all major racial subgroups in the USA followed by American Indian and Alaska Natives [43]. Disparities may be partly attributed to disproportionally lower socioeconomic status, comorbidities, prevalence of CRC risk factors, rates of screening, and access to healthcare [44]. Historically, marginalized racial and socioeconomic groups also have lower rates of CRC screening attributed to structural barriers like limited access to healthcare, lack of insurance, and reported lower rates of provider recommendations [44-47]. Unfortunately, in the USA, these groups among other marginalized populations also experienced higher rates of financial instability, unemployment, COVID19 infection, and mortality during the pandemic [48]. Many experts are proposing strategies to address the resulting challenges in screening and CRC care in underserved communities such as mailing at-home FIT tests, ensuring community health centers have support and access to colonoscopies, and increasing research in these groups $[49,50]$. Community-based studies are imperative to understand healthcare limitations and develop better strategies to serve these at- 
risk populations moving forward who have likely suffered the most from the pandemic.

We must also consider the pandemic effects in another unfortunate and increasingly prevalent group, young-onset CRC patients. In the past 3 decades, there has been a disturbing global rise in CRCs in individuals under 50 years of age [44]. These CRCs are more likely to be anatomically distal primaries and disproportionately diagnosed at advanced stages compared to CRCs in older patients. While the etiology of this trend has yet to be fully elucidated, in 2018, the American Cancer Society updated their recommendations to start averagerisk CRC screening at age 45 which was supported by the US Preventive Services Task Force in May 2021 [51, 52]. While we wait for studies to confirm this, there are concerns that delays in screening and seeking medical attention for early GI symptoms during the pandemic will result in more advanced diagnoses in young patients in the upcoming months to years. In the interim, it is important for providers to recognize concerning symptoms and promptly initiate evaluation as our medical systems emerge from pandemic constraints.

\section{Navigating institutional changes}

Many oncology departments found themselves restructuring, re-locating oncologists to care for COVID-19 patients, and frequently communicating updates at the height of the pandemic. One organization, New York Presbyterian Hospital systems, reported their experience in cancer leadership and resource management during the height of the pandemic in New York City, USA, a city that experienced exceptionally high rates of infection and resource constraints [53]. At Lombardi Comprehensive Cancer Center, we implemented departmentwide weekly meetings to discuss COVID-19 updates, safety concerns, and patient care. Similar to other institutions, we employed a system where we called patients prior to their appointments to screen for COVID-19 symptoms and redirected them to COVID-19 testing, the emergency department, a rescheduled in-person visit after a negative COVID-19 test, or a tele-visit if they screened positive. The entire department was briefed on pathways to follow when encountering patients displaying symptoms of COVID-19. Frequent weekly debriefings helped us share our experiences and brainstorm ways to improve our approach to clinical care and personal safety in unprecedented times.

\section{Clinic visits and digital health}

Most institutions, including ours, transitioned to primarily using tele-visits and significantly limiting in-person clinic appointments to minimize exposures at the height of the pandemic. Early surveys published by other institutions demonstrate variable levels of patient anxiety and overall favorable feedback on utilizing tele-visits [54-56]. In our experience, the majority of patients appreciated the convenience of a remote physician visit and felt their questions were appropriately addressed. Others conveyed tele-visits lacked the "humantouch" they desired from their treating teams and preferred an in-person experience. End-of-life and goals-of-care discussions can be especially emotionally challenging for patients and physicians through digital systems that 
minimize non-verbal communication.

Initially, our teams had to troubleshoot technical challenges such as connectivity issues, inaudibility, or poor video quality. Some patients did not have camera devices, and others were uncomfortable managing the technology. With streamlined COVID-19 testing, vaccination, and a trend towards normalization of hospital procedures, we are seeing more patients back in the clinic over the past few months. We have started offering stable patients the option for televisit, which are now significantly improved in quality, versus a clinic visit or alternating visit types when deemed appropriate. Most patients seem to favor this approach. We anticipate continuing tele-health visits for appropriate patients who are comfortable with this modality even after resolution of the pandemic.

\section{Systemic therapy}

Multiple expert oncology groups released recommendations for modifying standard-of-care (SOC) treatments to balance the benefits of systemic therapies against the risks of patient and healthcare personnel exposures to COVID-19 $[57,58,59 \bullet \bullet, 60 \bullet \bullet$ (Table 1). While all potential CRC scenarios and recommendations will not be reviewed here, the overarching themes were to reduce risks of COVID-19 infection by minimizing healthcare exposures, myelosuppression, and treatments with minimal benefit while still adequately controlling disease in the palliative setting and aggressively treating in the curative setting.

Proposed SOC treatment alterations included utilizing equivalent oral over intravenous drugs when feasible (such as choosing capecitabine in place of 5fluorouracil [5-FU]), alternative capecitabine scheduling to minimize toxicity, avoiding regimens with significant grade 3 or 4 toxicities, considering dose reductions proactively, and adding growth factors to minimize neutropenia [64-66]. Regimens like FOLFOXIRI and TAS-102, associated with 50\% and $38 \%$ rates of grade $3 / 4$ neutropenia, respectively, should be carefully considered or started with dose reductions to prevent excessive myelosuppression and hospitalizations $[67,68]$. Longer immunotherapy dosing intervals with similar pharmacokinetics were favored to reduce infusion visits [69, 70]. When using 5FU, experts recommended dropping the bolus which is associated with higher rates of hematologic toxicity and unclear survival benefit [71].

For oxaliplatin-based regimens in the metastatic setting, treatment breaks, intermittent oxaliplatin dosing, or de-escalating to pyrimidine analogue maintenance (favoring oral drugs) after 6 to 8 cycles of induction therapy are established treatment strategies that could especially be considered during the pandemic to minimize toxicities and healthcare visits [72-74]. In the stage II CRC, the marginal and controversial survival benefit with adjuvant fluoropyrimidine and no proven survival benefit with addition of oxaliplatin should be weighed against the risks of COVID-19 infectivity when considering treatment versus observation $[75,76]$. In stage III CRC where adjuvant chemotherapy has clear survival benefit, limiting treatment to 3 rather than 6 months based on the IDEA collaboration trial and thereby limiting toxicities and infection exposures without significantly sacrificing survival benefit should also be considered $[77 \bullet \bullet]$. Globally, groups have started to publish their experiences 


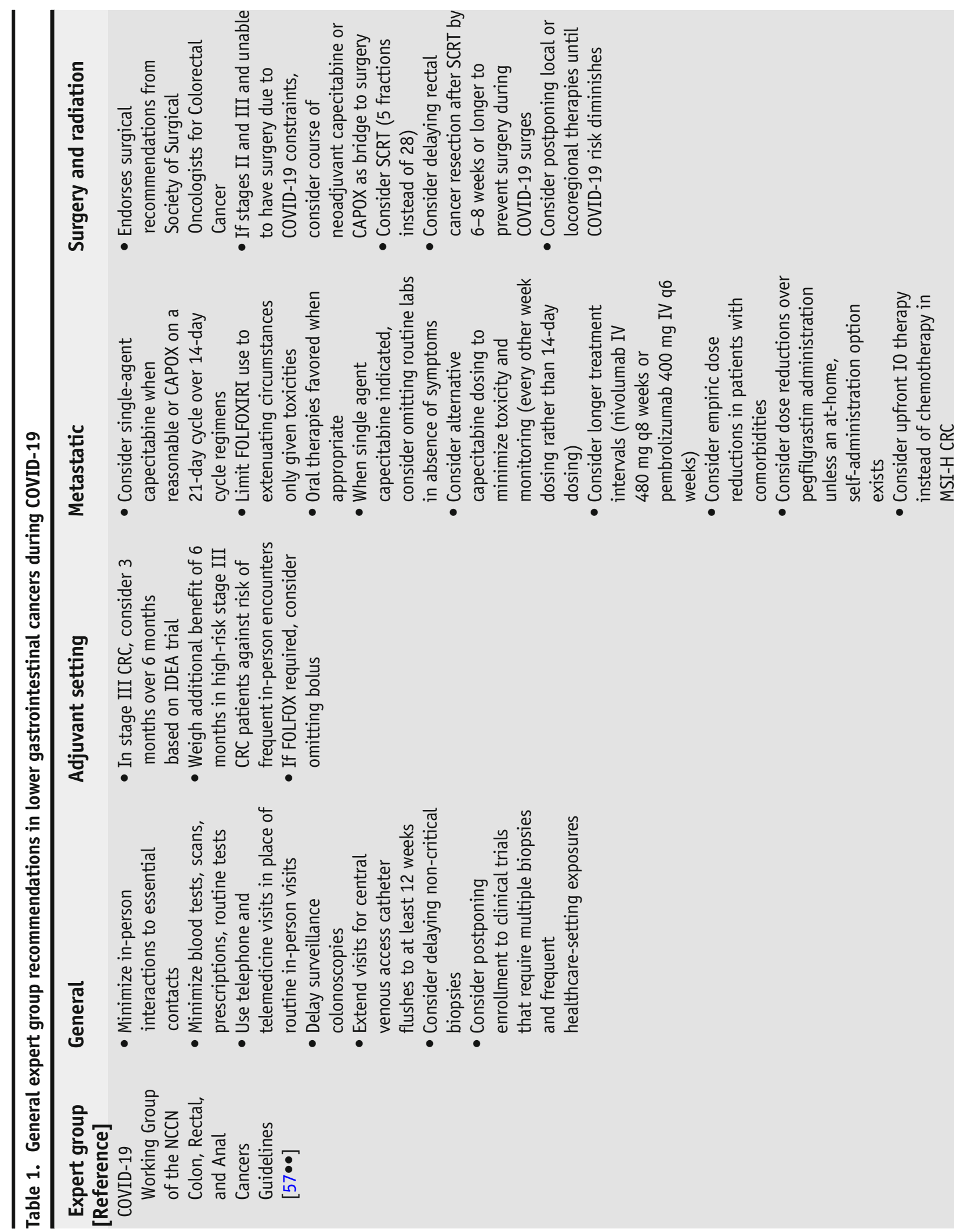



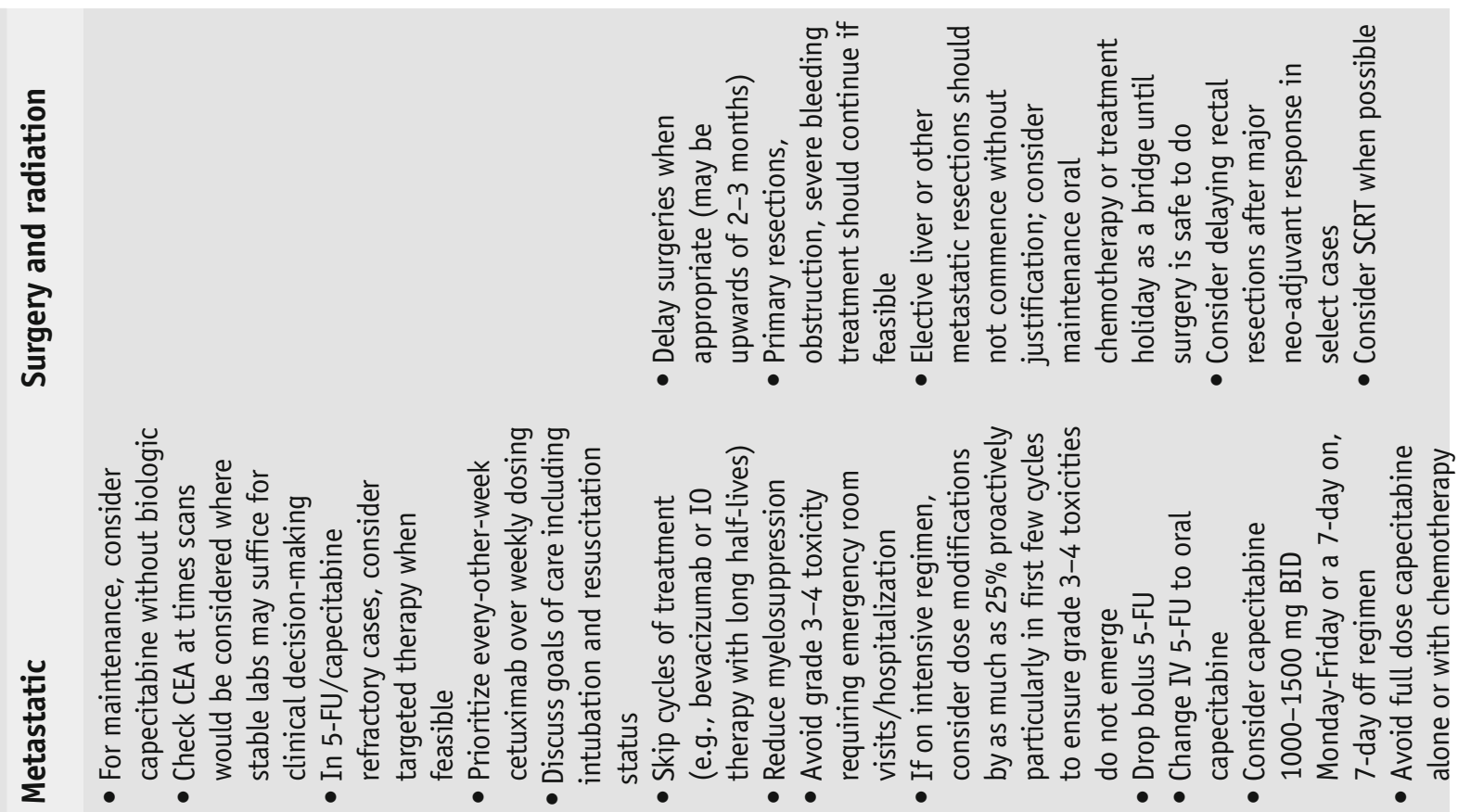

号
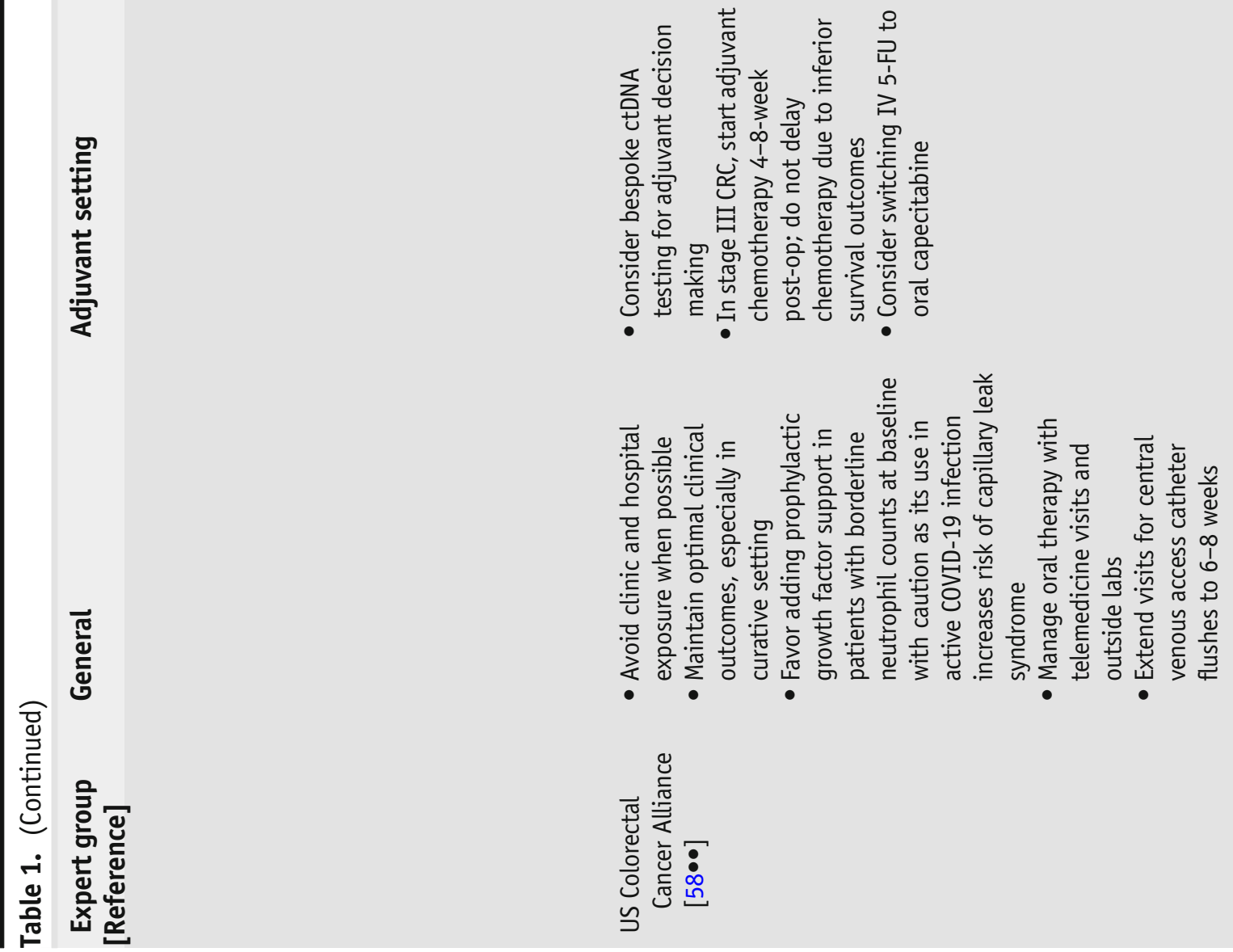


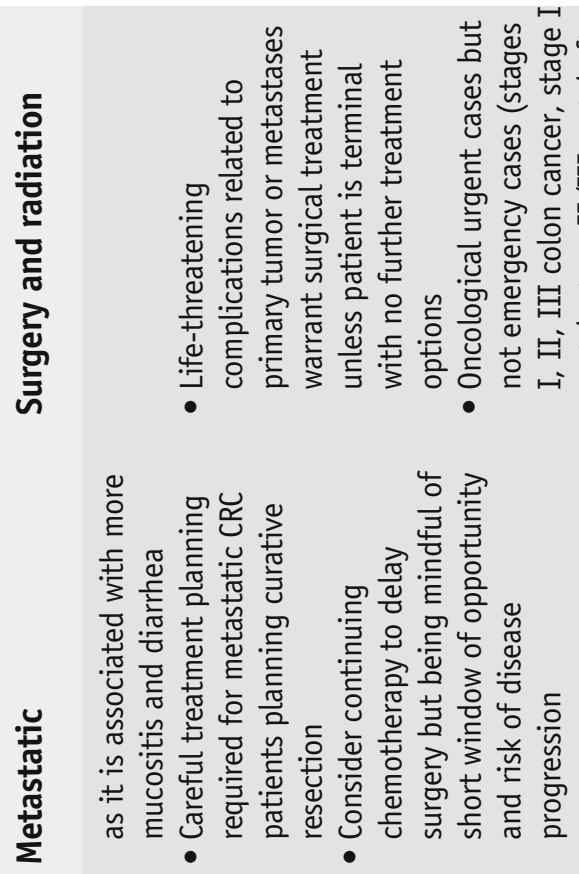

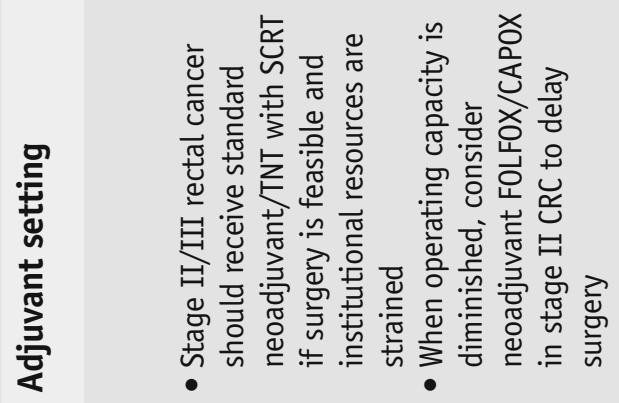

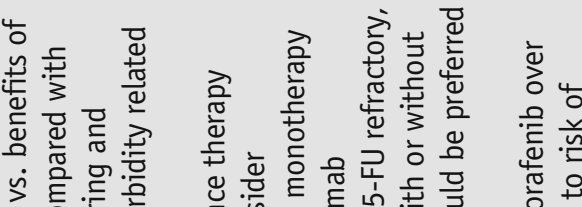

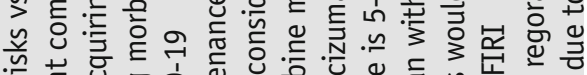

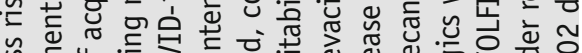

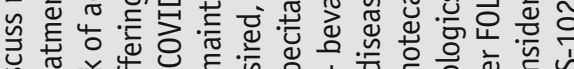

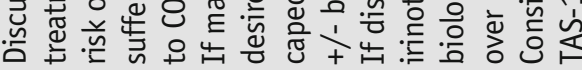

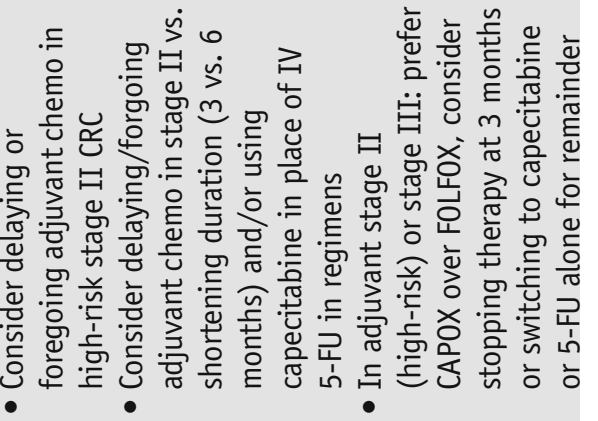

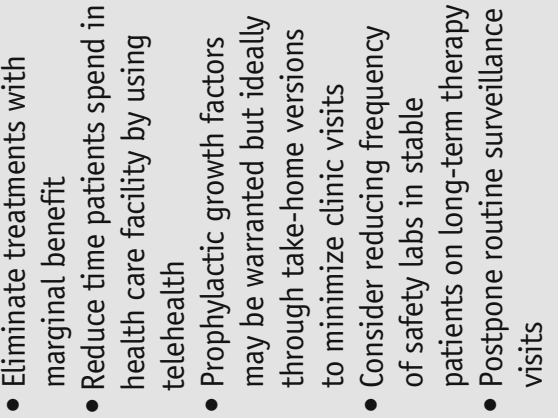

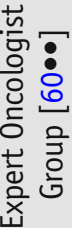




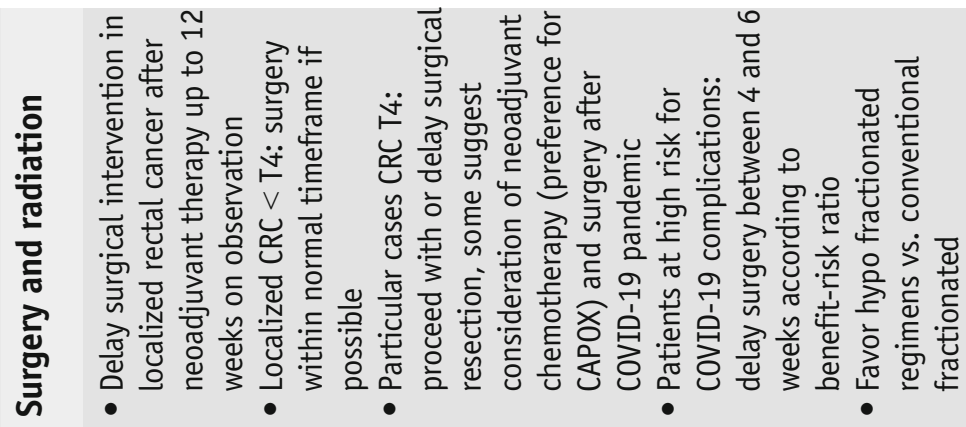

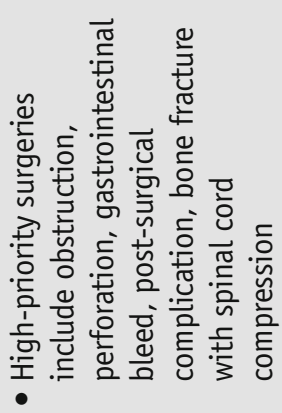

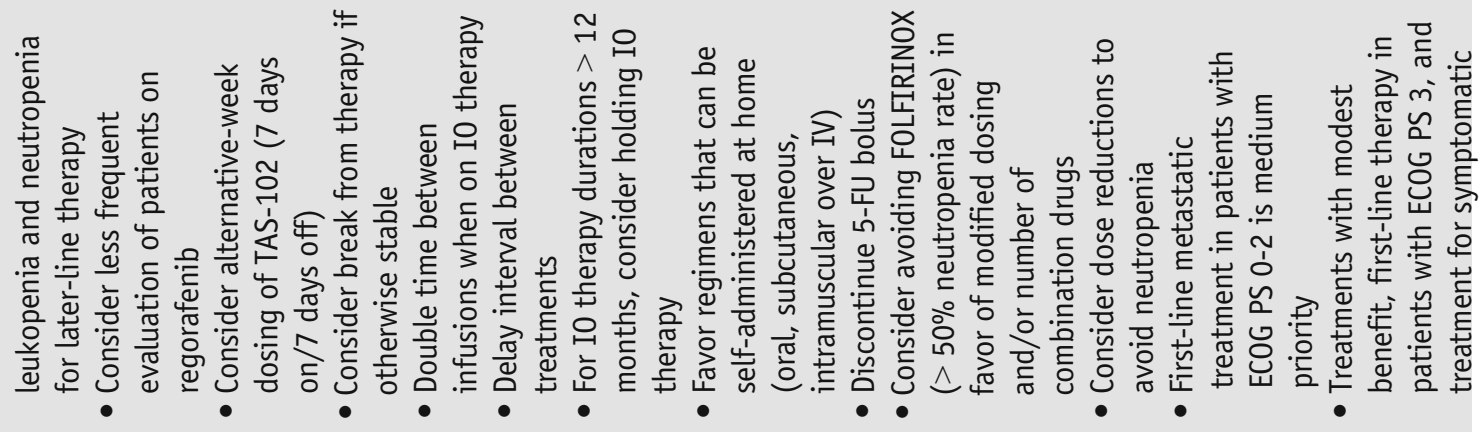
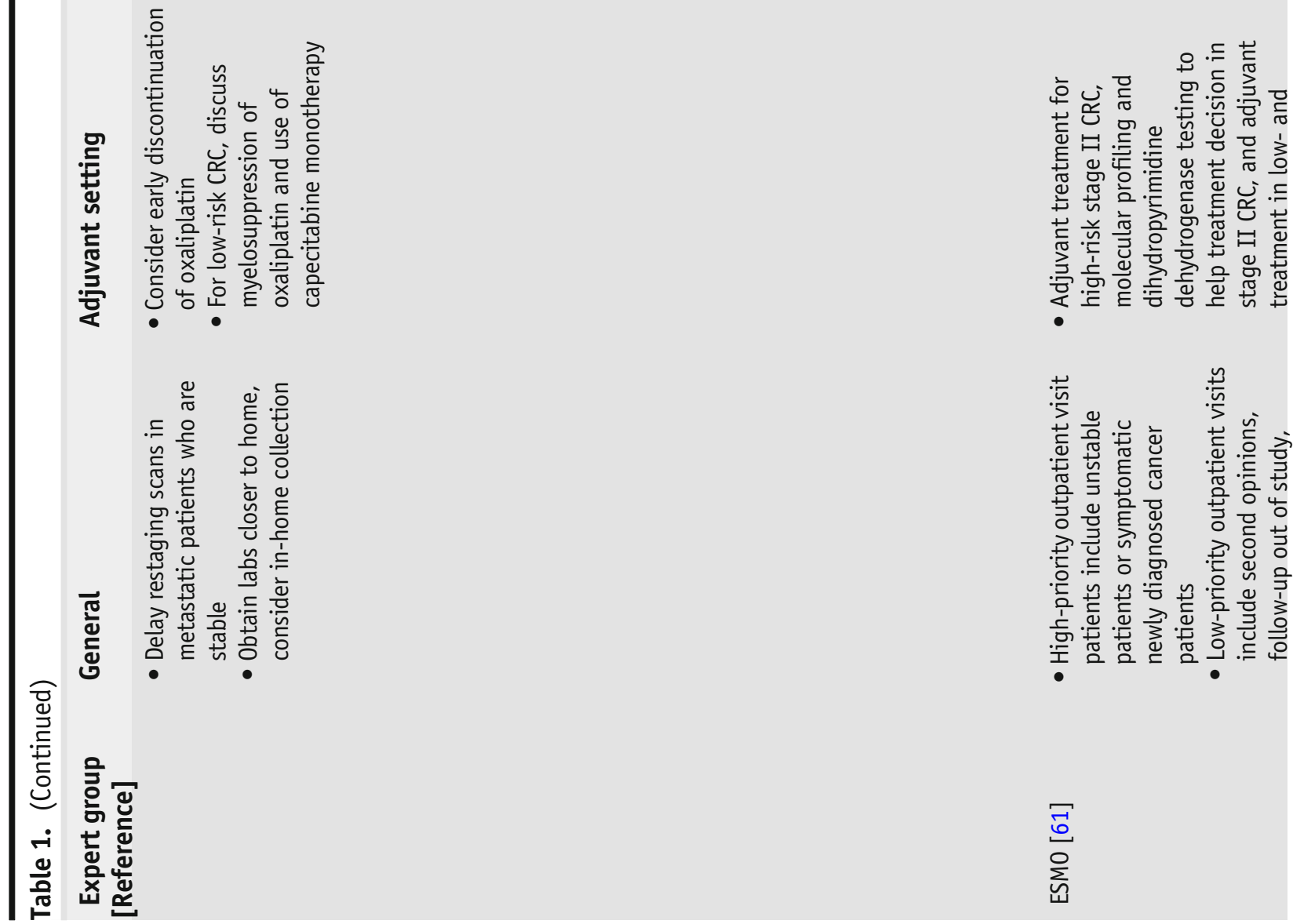

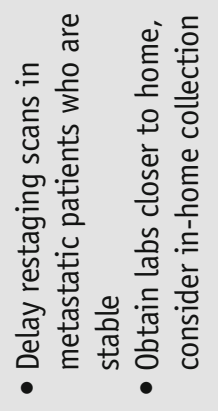

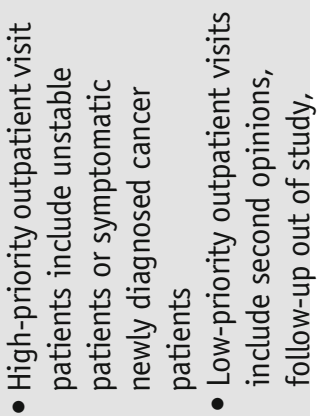

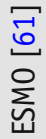



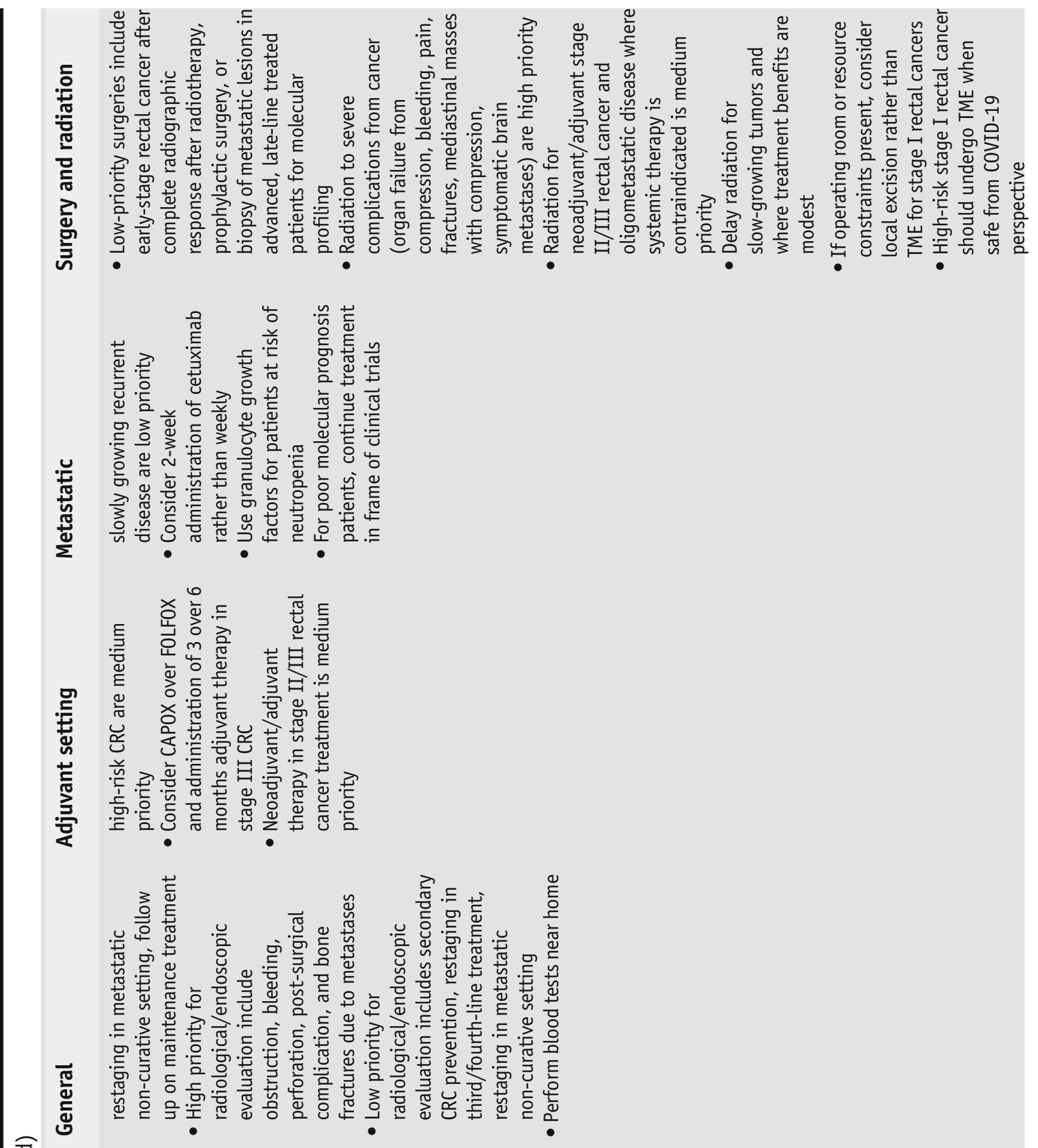

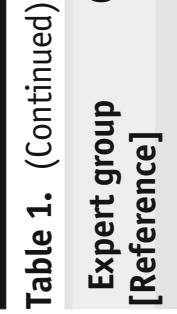

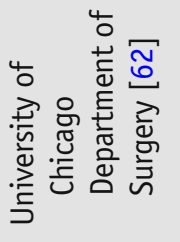




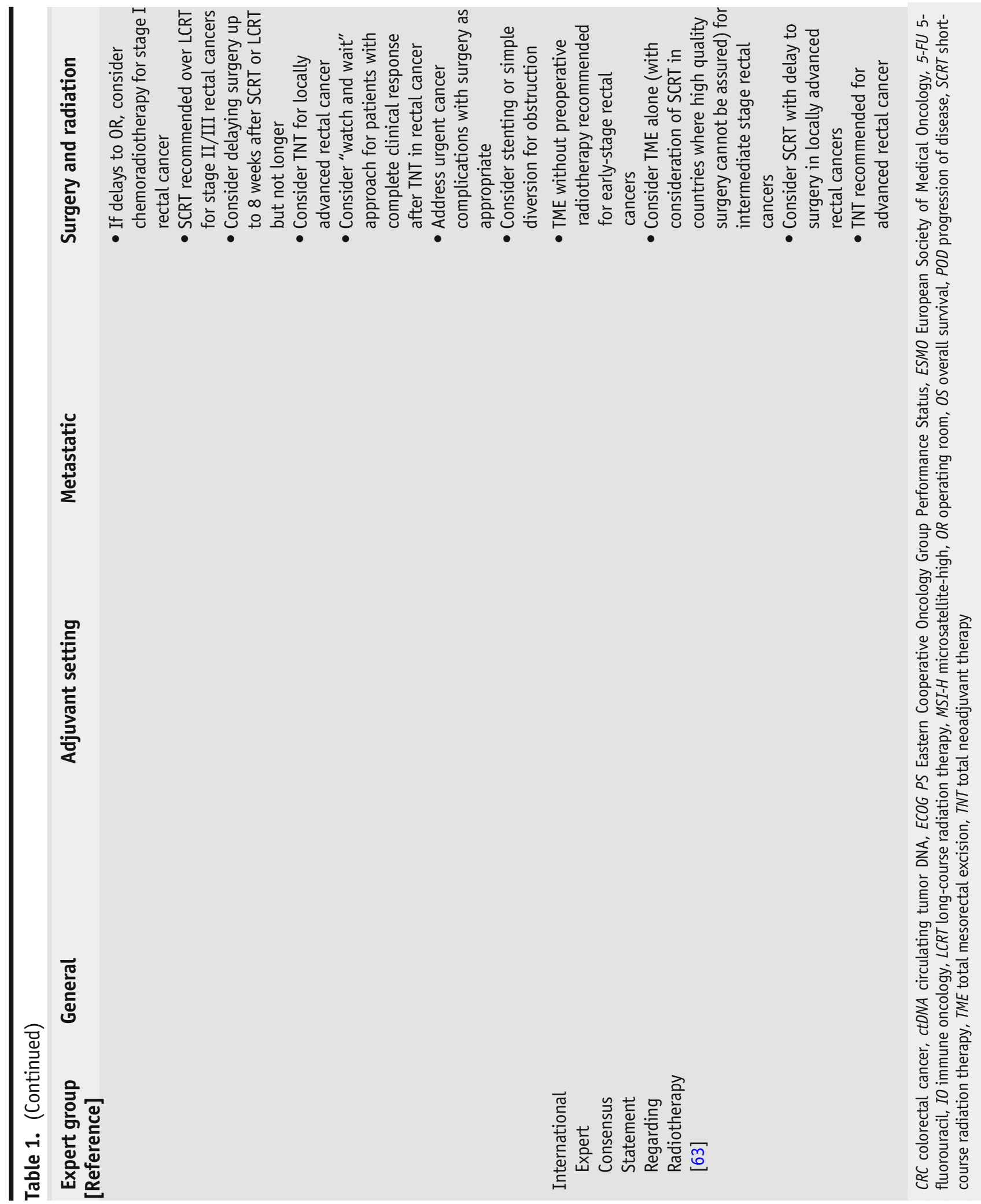


with treatment delays or modifications in CRC patients during the pandemic [78-80]. However, consequent survival outcomes will require long-term follow-up.

\section{Radiation therapy}

Radiation therapy is incorporated in SOC treatment for locally advanced, earlystage rectal cancer. It plays a more limited role in colon cancer for locoregional control and occasionally for oligometastatic disease with curative intent. During the pandemic, expert groups made recommendations for prioritization of radiation treatment based on optimization of locoregional control and survival benefit which were supported by the American Society of Radiation Oncology [61, 63] (Table 1). Severe complications such as cord compression, brain metastases, uncontrolled bleeding, fractures, and severe pain among others were prioritized, and neoadjuvant radiation regimens for advanced rectal cancer with curative potential were also recommended to continue without delay. In general, locoregional therapy for patients with metastatic cancer with limited survival benefit or for patients with slow-growing tumors was considered lower priority.

The general consensus has been to treat patients with SOC regimens modified to reduce COVID-19 exposures but without compromising survival outcomes. For instance, in early-stage rectal cancer, primarily T3 or T4 disease or any $\mathrm{T}$ with nodal disease, SOC treatment regimens include either short-course radiotherapy (SCRT) with immediate surgery or long-course radiotherapy (LCRT) combined with concurrent fluoropyrimidine-based chemotherapy and delayed surgery based on multi-disciplinary review [81]. Prior to the pandemic, the preferred approach in the USA was LCRT primarily due to concerns among providers for less tumor downsizing and increased toxicity with SCRT, albeit in the absence of randomized data [82]. However, in the pandemic setting, experts recommended pursuing shorter courses of radiation to reduce COVID-19 exposures and still maintain comparable survival benefits.

The non-inferiority Stockholm III trial suggested that recurrence outcomes were similar between SCRT ( $5 \times 5$ Gy radiation) with surgery within 1 week, SCRT with surgery after $4-8$ weeks, and LCRT $(25 \times 2$ Gy) with surgery after 4-8 weeks [83]. Comparable outcomes with short courses of pre-operative radiation were also demonstrated in other studies [84-86]. In addition, pathologic complete response rates were higher in SCRT patients who delayed surgery without significant differences in sphincter preservation and R0 resection rates [87]. The GRECCAR-6 trial reported extending the time from completion of radiotherapy to surgery from 7 to 11 weeks did not influence overall survival (OS), disease-free survival, distant recurrences, or local recurrences [88]. Promising results with neoadjuvant SCRT in combination with chemotherapy and immunotherapies were also seen in the RAPIDO trial and a phase II study, respectively, presented at the American Society of Clinical Oncology (ASCO) 2020 meeting [89•, 90]. Accordingly, expert consensus groups have recommended pursuing SCRT over LCRT and consideration of delaying surgery for definitive treatment during the COVID-19 pandemic in an effort to maintain treatment outcomes, treat more patients at a time, decrease linear accelerator usage, and simultaneously minimize the risks of patient and staff exposures to 
COVID-19 [63, 91] (Table 1).

An English National Health Service (NHS) study showed in April 2020 that the monthly proportion of SCRT to LCRT was $63 \%$ vs. $32 \%$ which had dramatically reversed compared to 2019 patterns when it was 19\% vs. 70\%, respectively [33]. In the USA, some cancer centers published their experiences and mandated all patients with locally advanced rectal cancer be treated with SCRT during the pandemic and even consider SCRT with total neoadjuvant therapy off-trial [92]. The current recommendations leading to increased use of SCRT in the USA may result in increased familiarity among providers, and it will be interesting to see if this leads to changes in treatment practices that last beyond the pandemic.

\section{Surgery}

The American College of Surgeons developed COVID-19 guidelines in March 2020 to triage surgical care depending on urgency of surgery, number of COVID-19 cases, and availability of hospital resources [93]. When resources were limited, routine and elective surgeries were deferred and attempt to delay surgery that would provide survival benefit with initiation or prolonging of neoadjuvant therapy where feasible was recommended. Patients with obstruction, perforation, bleeding, or impending complications were prioritized for surgery and alternatives such as diverting stomas and locoregional therapies like radiation were recommended if feasible.

The complications and risks of operating on patients during a pandemic also had to be considered. Doglietto et al. demonstrated a 9.5-fold increased risk of 30-day mortality and a 5-fold increased risk of complications in COVID-19 infected patients undergoing surgery compared to uninfected surgical patients [94]. A 35-fold higher risk of pulmonary complications and 13-fold higher risk of thrombotic complications were also noted. A meta-analysis reported a high global post-operative mortality rate of 20\% in COVID-19 patients [95]. While peri-surgical mortality in infected patients is demonstrated, other studies suggest the risks of contracting COVID-19 or increased mortality when operating on non-infected patients are less concerning. A French multi-center cohort study of 448 patients who underwent colorectal and anal cancer resection between January 1, 2020, and March 31, 2020, and returned to the pandemic environment reported an infection rate of $1.3 \%$ and no deaths until June 15, 2020 [30]. Based on the reassuring infection rate, the authors suggested there was no additional COVID-19-related mortality in patients having undergone CRC surgery. Similarly, an Italian study suggested that major CRC surgery during the COVID-19 pandemic in unaffected patients had comparable complication rates compared to pre-COVID-19 procedures [96]. It is important for multidisciplinary teams to discuss these considerations with patients when determining an optimal time for surgery while not compromising on survival outcomes especially in the curative setting.

Local and locoregional CRCs are associated with 5 -year OS rates of $90 \%$ and $72 \%$, respectively, which far exceed the more dismal $14 \%$ survival rate when metastatic [9]. Given the survival benefit with curative-intent surgery, expert groups strongly recommended pursuing definitive surgery and avoiding delays over 6 weeks from diagnoses which may be associated with inferior survival 
outcomes $[59,97]$. In the oligometastatic setting, the EORTC 40983 trial demonstrated a progression-free survival benefit when 6 cycles of FOLFOX were given before and after surgery compared to surgery alone [98]. Since most of these patients start with systemic therapy with the goal of controlling disease, downsizing tumors, or bridging to surgery, curative-intent oligometastatic resection timing tends to be more flexible. If tolerated, physicians may prolong neoadjuvant therapy to allow delays in surgery if resource limitations or safety concerns are present. As previously described, we advocate that locally advanced rectal cancers still undergo neoadjuvant therapy with a multi-disciplinary approach to determine the safest timing for surgery as delaying resection even up to 12 weeks may be acceptable without compromising survival benefit [83, 88].

Not surprisingly, the pandemic has led to decreased rates of CRC surgeries globally. The NHS England study revealed a 31\% relative reduction in CRC operations by April 2020 compared to 2019 operations [33]. Another international survey demonstrated that CRC surgery was delayed in $58.3 \%$ of divisions globally with $90 \%$ of delays ranging 5 to 8 weeks beyond normal wait times [99]. Grass et al. used the American College of Surgeons National Cancer Database to demonstrate that delaying surgery beyond 40 days in resectable CRC negatively impacted OS [97]. Larson et al. used this data in the context of COVID-19 and predicted the death of an additional 10,000 Americans over a 5year time period if CRC surgeries in stage I-III patients were delayed over 4 months [100]. We will inevitably learn more about the consequences of delayed procedures in select populations in the upcoming months to years.

\section{Management of COVID-19 infections}

The ASCO and National Comprehensive Cancer Network (NCCN) have released general recommendations for management of patients under investigation (PUI) for COVID-19 and for those who test positive [101, 102]. PUIs should delay cancer treatments and infusion center visits until their test results return, and if positive, referral to the emergency department versus at-home quarantine should be made at the discretion of the provider. For those that have confirmed infection, infusion services and cancer-directed therapy should be delayed at least 10 days from symptom onset or first positive RT-PCR test, and patients should have improvement of symptoms with $24 \mathrm{~h}$ without a fever in the absence of antipyretics prior to returning the infusion center or restarting cancer therapy. A study by Liu et al. suggested that mild to moderate COVID-19 cases have early viral clearance around day 10 post-symptom onset, but severe cases have longer infectivity that can last beyond 20 days post-symptom onset [103]. Therefore, assessing the severity of infection and immunosuppression can help determine the length of recommended isolation and treatment delay. For severely immunocompromised individuals, the CDC suggests a test-based approach in symptomatically improved patients with two consecutive RT-PCR tests over $24 \mathrm{~h}$ apart and consultation with infectious disease prior to discontinuing isolation procedures [104]. Recommendations for patients with significant COVID-19 exposures are also outlined by the NCCN [101].

Following the Food and Drug Administration (FDA) Emergency Use Authorizations (EUAs), high-risk outpatients including those with active cancer and immunosuppression with mild to moderate symptomatic COVID-19 infections 
could be considered for antispike neutralizing monoclonal antibodies bamlanivimab with or without etesvimab or casirivimab and imdevimab although the trials supporting their use do not detail the number of cancer patients included [105-108]. The antiviral remdesivir can be considered for those hospitalized with COVID-19 pneumonia with hypoxia but not yet requiring mechanical ventilation or extracorporeal membrane oxygenation, and glucocorticoids can also be considered although with unclear benefit in neutropenic and immunosuppressed patients [109-111]. Kalil et al. conducted a trial showing that baricitinib, an inhibitor of Janus kinase 1 and 2, in addition to remdesivir can be considered when glucocorticoids are contraindicated [112]. However, the baricitinib plus remdesivir arm only had 20 cancer and 17 immunocompromised patients out of 515 total patients, and the remdesivir control arm only had 17 cancer and 13 immunocompromised patients out of 518 total patients. In addition, convalescent plasma can be considered for hospitalized patients as there are some data supporting its use especially in those unable to mount an adequate humoral immune response [113, 114]. The NCCN guidelines provide more detailed rationale when considering these treatments [101]. Overall, we currently lack strong efficacy data of these treatments in cancer patients due to low numbers of oncology patients studied.

Finally, it is important to consider COVID-19 testing when working up neutropenic fever, a diagnosis commonly encountered in oncology patients. These patients should still be appropriately covered empirically with antibiotics. Oncologists should continue to use the ASCO and Infectious Diseases Society of America (IDSA) guidelines to evaluate which patients are appropriate for outpatient management with oral antibiotics to potentially minimize hospital exposures and which patients need prompt hospital admission for intravenous antibiotics and workup [115]. Extreme caution is advised when considering the use of granulocyte colony-stimulating factor (GCSF) in neutropenic patients with active COVID-19 infections. A few cases have reported rapid clinical deterioration after introducing GCSF in COVID-19 patients possibly attributed to the rise in cytokines and increased risk of capillary leak syndrome [116-118].

\section{COVID-19 vaccination}

On December 11, 2020, the FDA issued an EUA for the first COVID-19 mRNA vaccine made by Pfizer-BioNTech for emergency use. Since then, on December 18, 2020, and February 27, 2021, it granted EUAs for an mRNA vaccine by Moderna, Inc., and a viral vector vaccine by Janssen Biotech, Inc., respectively. The initial vaccine roll-out was challenging with limited availability, but now the rate of vaccination with the three authorized options on the market rises daily. The NCCN recommends cancer patients and their close contacts get vaccinated with any of the three vaccines whenever one becomes available to them [119].

We counsel patients on the efficacy and safety of the vaccines in the general population but review that the effectiveness and toxicities in cancer patients are not currently known as immunosuppressed patients and those on immune-modulating drugs were excluded from the vaccine trials [120122]. Prior studies suggest that other inactive vaccines are safe in cancer patients and still have efficacy even if patients are on chemotherapy although relative efficacy may vary based on tumor type $[123,124]$. The current COVID-19 vaccines also do not contain live or functional virus and 
thus are not expected to cause active infection in immunocompromised patients. Extrapolation from prior vaccine studies, IDSA guidelines, and the published COVID-19 vaccine studies supports the recommendation for patients to pursue vaccination as soon as possible while still carefully adhering to prevention guidelines [125].

The optimal timing of vaccination in relation to chemotherapy or immunotherapy cycles is unknown. An influenza vaccine study including breast and lung cancer patients receiving cytotoxic chemotherapy on a 3-week schedule reported comparable antibody responses between vaccinated patients on day 1 or day 11 during a cytopenic period of the cycle [126]. However, in practice, there are a myriad of regimens with different combinations of therapies, dosing levels, and degrees of myelosuppression. As many physicians believe corticosteroids that exceed physiologic doses may blunt vaccine immune responses, it may be reasonable to avoid vaccination within a few days of chemotherapy infusion if premedications include high-dose steroids. If feasible, oncologists may recommend adjusting the timing of vaccinations or rescheduling treatment infusions to avoid overlapping toxicities especially in highly symptomatic patients. The COVID-19 and Cancer Clinical Trials Working Group have also issued guidance on vaccination timing around clinical trial screening and advocates for including vaccinated patients in clinical trials that normally lists the use of other "investigational therapies" as an exclusion criteria [127]. In addition, the FDA clarified that the vaccines given under EUA are not considered "investigational products" [128]. Updates to efficacy, safety, and guidance for revaccination or boosters after immunosuppressive therapies will be issued as we learn more about the vaccine in cancer patients. For instance, the ongoing phase 3 "vaccination against COVID in cancer" (VOICE) trial will assess whether chemotherapies or immunotherapies affect how patients respond to mRNA COVID-19 vaccinations [129].

\section{Summary}

We are all eager for the pandemic to be over; none more than our patients. As our patients have had to stay away from friends and family and their critical emotional support systems, we know that they are suffering more than many. CRC care is a multi-disciplinary activity, and while we have been able to maintain interactive collaboration through remote conferencing, we, too, perform better when we are together. The COVID-19 pandemic forced us to make dramatic changes, many of which are for the better. Several lessons have been learned, reshaping our future practice. The stress of this event has left our medical community stronger and more focused. Our success will be measured by the mortality rates of CRC over the next several years.

\section{Declarations}

\section{Conflict of Interest}

Reetu Mukherji declares that she has no conflict of interest. John L. Marshall declares that he has no conflict of interest. 
Human and Animal Rights and Informed Consent

This article does not contain any studies with human or animal subjects performed by any of the authors.

\section{References and Recommended Reading}

Papers of particular interest, published recently, have been

highlighted as:

- Of importance

- Of major importance

1. Guan W, Ni Z, Hu Y, Liang W, Ou C, He J, et al. Clinical characteristics of coronavirus disease 2019 in China. N Engl J Med. 2020;382:1708-20.

2. Rosenthal N, Cao Z, Gundrum J, Sianis J, Safo S. Risk factors associated with in-hospital mortality in a US national sample of patients with COVID-19. JAMA Netw Open. 2020;3:e2029058.

3. Lu J, Gu J, Li K, Xu C, Su W, Lai Z, et al. COVID-19 outbreak associated with air conditioning in restaurant, Guangzhou, China, 2020. Emerg Infect Dis. 2020;26:1628-31.

4. Madewell ZJ, Yang Y, Longini IM, Halloran ME, Dean NE. Household transmission of SARS-CoV-2: a systematic review and meta-analysis. JAMA Netw Open. 2020;3:e2031756.

5. Hamner L, Dubbel P, Capron I, Ross A, Jordan A, Lee J, et al. High SARS-CoV-2 Attack rate following exposure at a choir practice - Skagit County, Washington, March 2020. MMWR Morb Mortal Wkly Rep. 2020;69:606-10.

6. Marks M, Millat-Martinez P, Ouchi D, Roberts $\mathrm{CH}$, Alemany A, Corbacho-Monne $\mathrm{M}$, et al. Transmission of COVID-19 in 282 clusters in Catalonia, Spain: a cohort study. Lancet Infect Dis.

2021;21:629-36.

7. Khanh NC, Thai PQ, Quach H-L, Thi N-AH, Dinh PC, Duong TN, et al. Transmission of SARS-CoV 2 during long-haul flight. Emerg Infect Dis. 2020;26:2617-24.

8. Johansson MA, Quandelacy TM, Kada S, Prasad PV, Steele M, Brooks JT, et al. SARS-CoV-2 Transmission from people without COVID-19 symptoms. JAMA Netw Open. 2021;4:e2035057.

9. Cancer of the colon and rectum - cancer stat facts [Internet]. SEER. [cited $2021 \mathrm{Feb} 1]$. Available from: https://seer.cancer.gov/statfacts/html/colorect.html

10. Pan J, Xin L, Ma Y-F, Hu L-H, Li Z-S. Colonoscopy reduces colorectal cancer incidence and mortality in patients with non-malignant findings: a meta-analysis. Am J Gastroenterol. 2016;111:355-65.

11. World Health Organization. COVID-19 weekly epidemiological update [Internet]. World Health Organization; 2021 [cited 2021 Apr 7]. Available from: https:// www.who.int/publications/m/item/weeklyepidemiological-update-on-covid-19\%2D\%2D-6april-2021

12. Kuderer NM, Choueiri TK, Shah DP, ShyrY, Rubinstein SM, Rivera DR, et al. Clinical impact of COVID-19 on 
23. Brar G, Pinheiro LC, Shusterman M, Swed B, Reshetnyak E, Soroka O, et al. COVID-19 Severity and outcomes in patients with cancer: a matched cohort study. JCO. 2020;38:3914-24.

24. Tsotra E, Gousis C, Russell B, Moss C, Palmer K, Montes A, et al. COVID-19 infection in gastrointestinal (GI) cancer patients receiving systemic anticancer treatment (SACT) during the outbreak of the pandemic: the Guy's cancer centre experience. JCO. 2021;39:455.

25. Erdal GS, Polat O, Erdem GU, Korkusuz R, Hindilerden F, Yilmaz M, et al. The mortality rate of COVID-19 was high in cancer patients: a retrospective single-center study. Int J Clin Oncol. 2021;26:826-34.

26. Yang K, Sheng Y, Huang C, Jin Y, Xiong N, Jiang K, et al. Clinical characteristics, outcomes, and risk factors for mortality in patients with cancer and COVID-19 in Hubei, China: a multicentre, retrospective, cohort study. Lancet Oncol. 2020;21:904-13.

27. Centers for Disease Control: Underlying medical conditions associated with high risk for severe COVID-19: information for healthcare Provders.https://www.cdc. gov/coronavirus/2019-ncov/hcp/clinical-care/ underlyingconditions.html 2021. Accessed 04 Apr 2021.

28. Garassino MC, Whisenant JG, Huang L-C, Trama A, Torri V, Agustoni F, et al. COVID-19 in patients with thoracic malignancies (TERAVOLT): first results of an international, registry-based, cohort study. Lancet Oncol. 2020;21:914-22.

29. Lee LYW, Cazier J-B, Starkey T, Briggs SEW, Arnold R, Bisht $\mathrm{V}$, et al. COVID-19 prevalence and mortality in patients with cancer and the effect of primary tumour subtype and patient demographics: a prospective cohort study. Lancet Oncol. 2020;21:1309-16.

30. Tuech J-J, Manceau G, Ouaissi M, Denet C, Chau A, Kartheuser A, et al. Are colorectal cancer patients at risk for COVID-19 infection during the postoperative period? The Covid-GRECCAR study. Int J Color Dis. 2021;36:611-5.

31. Rana SS. Risk of COVID-19 transmission during gastrointestinal endoscopy. J Dig Endosc. 2020;11:27-30.

32. Doubeni CA, Corley DA, Quinn VP, Jensen CD, Zauber AG, Goodman M, et al. Effectiveness of screening colonoscopy in reducing the risk of death from right and left colon cancer: a large community-based study. Gut. 2018;67:291-8.

33. Morris EJA, Goldacre R, Spata E, Mafham M, Finan PJ, Shelton J, et al. Impact of the COVID19 pandemic on the detection and management of colorectal cancer in England: a populationbased study. Lancet Gastroenterol Hepatol. 2021;6:199-208.

34. Rutter MD, Brookes M, Lee TJ, Rogers P, Sharp L. Impact of the COVID-19 pandemic on UK endoscopic activity and cancer detection: a national endoscopy database analysis. Gut. 2021;70:537-43.
35. Kaufman HW, Chen Z, Niles J, Fesko Y. Changes in the number of us patients with newly identified cancer before and during the coronavirus disease 2019 (COVID-19) pandemic. JAMA Netw Open. 2020;3:e2017267.

36.• Gawron AJ, Kaltenbach T, Dominitz JA. The impact of the coronavirus disease-19 pandemic on access to endoscopy procedures in the VA healthcare system. Gastroenterology. 2020;159:1216-1220.e1

One of the largest integrated health care systems in the United States, the Veterans Affairs health system, reported dramatic reductions in upper endoscopy and colonoscopies during the COVID-19 pandemic.

37. Meester RGS, Zauber AG, Doubeni CA, Jensen CD, Quinn VP, Helfand M, et al. Consequences of increasing time to colonoscopy examination after positive result from fecal colorectal cancer screening test. Clin Gastroenterol Hepatol. 2016;14:14451451.e8.

38. Degeling K, Baxter NN, Emery J, Franchini F, Gibbs P, Mann GB, et al. An inverse stage-shift model to estimate the excess mortality and health economic impact of delayed access to cancer services due to the COVID19 pandemic. medRxiv. 2020;2020(05):30.20117630.

39. Sharpless NE. COVID-19 and cancer. Science. 2020;368:1290.

40. Perkons N, Kim C, Boedec C, Schneider CJ, Teitelbaum UR, Ben-Josef E, et al. Quantifying the impact of the COVID-19 pandemic on gastrointestinal cancer care delivery. JCO. 2021;39:30.

41. Issaka RB, Somsouk M. Colorectal cancer screening and prevention in the COVID-19 era. JAMA Health Forum. 2020;1:e200588.

42. Myint A Impact of the COVID-19 pandemic on colorectal cancer screening rates and modalities in a large integrated health system. 2020 In: https://gi.org/ media/press-info-scientific-meeting/featured-science/ p0761-impact-of-the-covid-19-pandemic-oncolorectal-cancer-screening-rates-and-modalities-in-alarge-integrated-health-system/. Accessed 07 April 2021.

43. Siegel RL, Miller KD, Fuchs HE, Jemal A. Cancer statistics, 2021. CA Cancer J Clin. 2021;71:7-33.

44. Siegel RL, Miller KD, Sauer AG, Fedewa SA, Butterly LF, Anderson JC, et al. Colorectal cancer statistics, 2020. CA Cancer J Clin. 2020;70:145-64.

45. May FP, Almario CV, Ponce N, Spiegel BMR. Racial minorities are more likely than whites to report lack of provider recommendation for colon cancer screening. Am J Gastroenterol. 2015;110:1388-94.

46. Warren Andersen S, Blot WJ, Lipworth L, Steinwandel M, Murff HJ, Zheng W. Association of race and socioeconomic status with colorectal cancer screening, colorectal cancer risk, and mortality in southern US adults. JAMA Netw Open. 2019;2:e1917995.

47. Carethers JM, Doubeni CA. Causes of socioeconomic disparities in colorectal cancer and intervention 
framework and strategies. Gastroenterology. 2020;158:354-67.

48. Lopez L, Hart LH, Katz MH. Racial and ethnic health disparities related to COVID-19. JAMA. 2021;325:719.

49. Nodora JN, Gupta S, Howard N, Motadel K, Propst T, Rodriguez J, et al. The COVID-19 pandemic: identifying adaptive solutions for colorectal cancer screening in underserved communities. J Natl Cancer Inst. 2020:djaa 117

50. Balzora S, Issaka RB, Anyane-Yeboa A, Gray DM, May FP. Impact of COVID-19 on colorectal cancer disparities and the way forward. Gastrointest Endosc. 2020;92:946-50.

51. Wolf AMD, Fontham ETH, Church TR, Flowers CR, Guerra CE, LaMonte SJ, et al. Colorectal cancer screening for average-risk adults: 2018 guideline update from the American Cancer Society. CA Cancer J Clin. 2018;68:250-81.

52. US Preventive Services Task Force, Davidson KW, Barry MJ, Mangione CM, Cabana M, Caughey AB, et al. Screening for colorectal cancer: US preventive services task force recommendation statement. JAMA. 2021;325:1965.

53. Shah MA, Emlen MF, Shore T, Mayer S, Leonard JP, Rossi A, et al. Hematology and oncology clinical care during the coronavirus disease 2019 pandemic. CA Cancer J Clin. 2020;70:349-54.

54. Kamposioras K, Lim KHJ, Saunders MP, Marti K, Anderson $\mathrm{D}$, Cutting $\mathrm{M}$, et al. The impact of changes in service delivery in patients with colorectal cancer during the first peak of the COVID-19 pandemic. JCO. 2021;39:28.

55. Garcia R, Dwyer A, McDonnell M. Understanding the impact of COVID-19 on the colorectal cancer community: barriers and opportunities for care. JCO. 2021;39:29.

56. Jiang CY, El-Kouri NT, Elliot D, Shields J, Caram MEV, Frankel TL, et al. Telehealth for cancer care in veterans: opportunities and challenges revealed by COVID. JCO Oncol Pract. 2020;17:22-9.

57. National Comprehensive Cancer Network. Principles of management of colorectal cancer patients during the COVID-19 pandemic. 2020. https://www.nccn.org/ covid-19/pdf/Colorectal\%20COVID-19.pdf. Accessed March 09, 2021.

58. Marshall JL, Yarden RI, Weinberg BA. Colorectal cancer care in the age of coronavirus: strategies to reduce risk and maintain benefit. Colorectal Cancer. 2020;9:1.

59.• O'Leary MP, Choong KC, Thornblade LW, Fakih MG, Fong Y, Kaiser AM. Management Considerations for the Surgical Treatment of Colorectal Cancer During the Global Covid-19 Pandemic. Ann Surg. 2020;272:e98105

Expert recommendations in colon cancer surgical management during the COVID-19 pandemic.

60.• Lou E, Beg S, Bergsland E, Eng C, Khorana A, Kopetz S, et al. Modifying practices in GI oncology in the face of COVID-19: recommendations from expert oncologists on minimizing patient risk. JCO Oncol Pract.
2020;16:383-8

Expert comprehensive recommendations in colon cancer management during the COVID-19 pandemic.

61. Vecchione L, Stintzing S, Pentheroudakis G, Douillard J-Y, Lordick F. ESMO management and treatment adapted recommendations in the COVID-19 era: colorectal cancer. ESMO Open. 2020;5:e000826.

62. Skowron KB, Hurst RD, Umanskiy K, Hyman NH, Shogan BD. Caring for patients with rectal cancer during the COVID-19 pandemic. J Gastrointest Surg. 2020;24:1698-703.

63. Marijnen CAM, Peters FP, Rödel C, Bujko K, Haustermans K, Fokas E, et al. International expert consensus statement regarding radiotherapy treatment options for rectal cancer during the COVID 19 pandemic. Radiother Oncol. 2020;148:213-5.

64. Aguado C, García-Paredes B, Sotelo MJ, Sastre J, DíazRubio E. Should capecitabine replace 5-fluorouracil in the first-line treatment of metastatic colorectal cancer? World J Gastroenterol. 2014;20:6092-101.

65. Sun JF, Wu RR, Norris C, Noone A-M, Amankwa-Sakyi $M$, Slack R, et al. Safety of chronic low-dose capecitabine as maintenance therapy in gastrointestinal cancers. Gastrointest Cancer Res. 2009;3:134-40.

66. Bryson E, Sakach E, Patel U, Watson M, Hall K, Draper A, et al. Safety and efficacy of 7 days on $/ 7$ days off versus 14 days on/7 days off schedules of capecitabine in patients with metastatic colorectal cancer: a retrospective review. Clin Colorectal Cancer. 2021;20:153-60.

67. Falcone A, Ricci S, Brunetti I, Pfanner E, Allegrini G, Barbara C, et al. Phase III trial of infusional fluorouracil, leucovorin, oxaliplatin, and irinotecan (FOLFOXIRI) compared with infusional fluorouracil, leucovorin, and irinotecan (FOLFIRI) as first-line treatment for metastatic colorectal cancer: the Gruppo Oncologico Nord Ovest. J Clin Oncol. 2007;25:16706.

68. Mayer RJ, Van Cutsem E, Falcone A, Yoshino T, GarciaCarbonero R, Mizunuma N, et al. Randomized trial of TAS-102 for refractory metastatic colorectal cancer. N Engl J Med. 2015;372:1909-19.

69. Long GV, Tykodi SS, Schneider JG, Garbe C, Gravis G, Rashford M, et al. Assessment of nivolumab exposure and clinical safety of $480 \mathrm{mg}$ every 4 weeks flat-dosing schedule in patients with cancer. Ann Oncol. 2018;29:2208-13.

70. Lala M, Akala O, Chartash E, Kalabis M, Su S-C, de Alwis D, et al. Abstract CT042: pembrolizumab $400 \mathrm{mg}$ Q6W dosing: first clinical outcomes data from keynote-555 cohort B in metastatic melanoma patients. Cancer Res. 2020;80:CT042.

71. Yoshida Y, Hasegawa J, Nezu R, Mikata S, Kim Y, Nishimura J, et al. Clinical significance of bolus 5-fluorouracil for recurrent or metastatic colorectal cancer treated with FOLFOX therapy. JCO. 2010;28:e14078. 
72. Hochster HS, Grothey A, Hart L, Rowland K, Ansari R, Alberts $S$, et al. Improved time to treatment failure with an intermittent oxaliplatin strategy: results of CONcePT. Ann Oncol. 2014;25:1172-8.

73. Maindrault-Goebel F, Lledo G, Chibaudel B, Mineur L, Andre T, Bennamoun $M$, et al. Final results of OPTIMOX2, a large randomized phase II study of maintenance therapy or chemotherapy-free intervals (CFI) after FOLFOX in patients with metastatic colorectal cancer (MRC): A GERCOR study. JCO. 2007;25:4013.

74. Simkens LHJ, van Tinteren H, Punt CJA, Koopman M. Maintenance treatment in metastatic colorectal cancer. Lancet Oncol. 2015;16:e582-3.

75. Kannarkatt J, Joseph J, Kurniali PC, Al-Janadi A, Hrinczenko B. Adjuvant chemotherapy for stage ii colon cancer: a clinical dilemma. JOP.

2017;13:233-41

76. Tournigand C, André T, Bonnetain F, Chibaudel B, Lledo G, Hickish T, et al. Adjuvant therapy with fluorouracil and oxaliplatin in stage ii and elderly patients (between ages 70 and 75 years) with colon cancer: subgroup analyses of the multicenter international study of oxaliplatin, fluorouracil, and leucovorin in the adjuvant treatment of colon cancer trial. JCO. 2012;30:3353-60.

77.• André T, Meyerhardt J, Iveson T, Sobrero A, Yoshino T, Souglakos I, et al. Effect of duration of adjuvant chemotherapy for patients with stage III colon cancer (IDEA collaboration): final results from a prospective, pooled analysis of six randomised, phase 3 trials. Lancet Oncol. 2020;21:1620-9

Prospective, pooled analysis of 6 randomized phase III trials failed to demonstrate non-inferiority of 3 months versus 6 months of adjuvant FOLFOX or CAPOX in stage III colorectal cancers. However, the absolute difference in 5-year overall survival was only $0.4 \%$ and survival data combined with reduced toxicities supported 3 months of adjuvant CAPOX use in most patients.

78. Sun L, Xu Y, Zhang T, Yang Y. Impact of the COVID-19 outbreak on adjuvant chemotherapy for patients with stage II or III colon cancer: experiences from a multicentre clinical trial in China. Curr Oncol. 2020;27:159-62.

79. Power R, O'Donohoe C, Enright C, Glennon L, McDowell L, Gallagher DJ, et al. Analysis of systemic therapy delivery for gastrointestinal cancer patients during the COVID-19 pandemic. JCO. 2020;38:301.

80. Baxter MA, Murphy J, Cameron D, Jordan J, Crearie C, Lilley C, et al. The impact of COVID-19 on systemic anticancer treatment delivery in Scotland. Br J Cancer. 2021;124:1353-6.

81. National Comprehensive Cancer Network. Colon cancer (Version 2.2021). https://www.nccn.org/ professionals/physician_gls/pdf/colon.pdf. Accessed May 29, 2021.

82. Mowery YM, Salama JK, Zafar SY, Moore HG, Willett CG, Czito BG, et al. Neoadjuvant long-course chemoradiation remains strongly favored over short-course radiotherapy by radiation oncologists in the United States. Cancer. 2017;123:1434-41.

83. Erlandsson J, Holm T, Pettersson D, Berglund A, Cedermark B, Radu C, et al. Optimal fractionation of preoperative radiotherapy and timing to surgery for rectal cancer (Stockholm III): a multicentre,

randomised, non-blinded, phase 3, non-inferiority trial. Lancet Oncol. 2017;18:336-46.

84. Ngan SY, Burmeister B, Fisher RJ, Solomon M, Goldstein D, Joseph D, et al. randomized trial of shortcourse radiotherapy versus long-course chemoradiation comparing rates of local recurrence in patients with T3 rectal cancer: Trans-Tasman Radiation Oncology Group Trial 01.04. JCO. 2012;30:3827-33.

85. Bujko K, Nowacki MP, Nasierowska-Guttmejer A, Michalski W, Bebenek M, Pudełko M, et al. Sphincter preservation following preoperative radiotherapy for rectal cancer: report of a randomised trial comparing short-term radiotherapy vs. conventionally fractionated radiochemotherapy. Radiother Oncol. 2004;72:1524.

86. Dutta SW, Alonso CE, Jones TC, Waddle MR, Janowski E-M, Trifiletti DM. Short-course versus long-course neoadjuvant therapy for non-metastatic rectal cancer: patterns of care and outcomes from the national cancer database. Clin Colorectal Cancer. 2018;17:297-306.

87. Bujko K, Partycki M, Pietrzak L. Neoadjuvant radiotherapy ( $5 \times 5 \mathrm{~Gy})$ : immediate versus delayed surgery. Recent Results Cancer Res. 2014;203:171-87.

88. Lefèvre JH, Mineur L, Cachanado M, Denost Q, Rouanet $\mathrm{P}$, de Chaisemartin $\mathrm{C}$, et al. Does A longer waiting period after neoadjuvant radio-chemotherapy improve the oncological prognosis of rectal cancer?: three years' follow-up results of the greccar-6 randomized multicenter trial. Ann Surg. 2019;270:747-54.

89. Hospers G, Bahadoer RR, Dijkstra EA, van Etten B, Marijnen C, Putter H, et al. Short-course radiotherapy followed by chemotherapy before TME in locally advanced rectal cancer: The randomized RAPIDO trial. JCO. 2020;38:4006

This prospective phase III trial in high risk locally advanced rectal cancers found adding neoadjuvant chemotherapy to neoadjuvant chemoradiation resulted in statistically significant higher complete response rates and lower rates of distant metastases compared to the standard practice of neoadjuvant chemoradiation and optional adjuvant chemotherapy.

90. Lin Z, Cai M, Zhang P, Li X, Cai K, Nie X, et al. Shortcourse radiotherapy and subsequent CAPOX plus camrelizumab followed by delayed surgery for locally advanced rectal cancer: Short-term results of a phase II trial. JCO. 2021;39:63.

91. Felice FD, Petrucciani N. Treatment approach in locally advanced rectal cancer during coronavirus (COVID19) pandemic: long course or short course? Color Dis. 2020;22:642-3.

92. Romesser PB, Wu AJ, Cercek A, Smith JJ, Weiser M, Saltz L, et al. Management of locally advanced rectal cancer during the covid-19 pandemic: a necessary 
paradigm change at Memorial Sloan Kettering Cancer Center. Adv Radiat Oncol. 2020;5:687-9.

93. ACS Cancer Programs. ACS guidelines for triage and management of elective cancer surgery cases during the acute and recovery phases of the coronavirus disease 2019 (COVID-19) pandemic. In: American College of Surgeons Clinical Issues and Guidance. ACS. 2020. https://www.facs.org/-/media/files/covid19/acs_ triage_and_management_elective_cancer_surgery_ during_acute_and_recovery_phases.ashx. Accessed 24 Mar 2021.

94. Doglietto F, Vezzoli M, Gheza F, Lussardi GL, Domenicucci M, Vecchiarelli L, et al. Factors associated with surgical mortality and complications among patients with and without coronavirus disease 2019 (COVID-19) in Italy. JAMA Surg. 2020;155:691.

95. Abate SM, Mantefardo B, Basu B. Postoperative mortality among surgical patients with COVID-19: a systematic review and meta-analysis. Patient Saf Surg. 2020;14:37.

96. Spinelli A, Carvello M, Carrano FM, Pasini F, Foppa C, Taffurelli G, et al. Reduced length of stay after 1057 elective colorectal surgery during the peak phase of 1058 Covid-19 pandemic: a positive effect of infection risk awareness? Surgery.

2020;20:30852-7.

97. Grass F, Behm KT, Duchalais E, Crippa J, Spears GM, Harmsen WS, et al. Impact of delay to surgery on survival in stage I-III colon cancer. Eur J Surg Oncol. 2020;46:455-61.

98. Nordlinger B, Sorbye H, Glimelius B, Poston GJ, Schlag $\mathrm{PM}$, Rougier $\mathrm{P}$, et al. Perioperative chemotherapy with FOLFOX4 and surgery versus surgery alone for resectable liver metastases from colorectal cancer (EORTC Intergroup trial 40983): a randomised controlled trial Lancet. 2008;371:1007-16.

99. Santoro GA, Grossi U, Murad-Regadas S, Nunoo-Mensah JW, Mellgren A, Di Tanna GL, et al. DElayed COloRectal cancer care during COVID-19 Pandemic (DECOR-19): global perspective from an international survey. Surgery. 2021;169:796-807.

100. Larson DW, Aziz MAAE, Mandrekar JN. How many lives will delay of colon cancer surgery cost during the COVID-19 pandemic? An analysis based on the US national cancer database. Mayo Clin Proc. 2020;95:1805-7.

101. National Comprehensive Cancer Center. NCCN best practice guidance: management of COVID-19 (March 2021). https://www.nccn.org/docs/default-source/ covid-19/2021-covid-infectiousdisease-management. pdf?sfvrsn=63f70c30_7. Accessed April 08, 2021.

102. American Society of Clinical Oncology. ASCO special report: a guide to cancer delivery during the COVID19 pandemic (Updated December 15, 2020). https:// www.asco.org/sites/new-www.asco.org/files/ contentfiles/2020-ASCO-Guide-Cancer-COVID19. pdf. Accessed March 19, 2021.
103. Liu Y, Yan L-M, Wan L, Xiang T-X, Le A, Liu J-M, et al. Viral dynamics in mild and severe cases of COVID-19. Lancet Infect Dis. 2020;20:656-7.

104. Centers for Disease Control and Prevention: Discontinuation of transmission-based precaution and disposition of patients with SARS-CoV-2 infection in healthcare settings. https://www.cdc.gov/ coronavirus/2019-ncov/hcp/dispositionhospitalized-patients.html. Accessed 08 Apr 2021.

105. Gottlieb RL, Nirula A, Chen P, Boscia J, Heller B, Morris J, et al. Effect of bamlanivimab as monotherapy or in combination with etesevimab on viral load in patients with mild to moderate COVID-19: a randomized clinical trial. JAMA. 2021;325:632.

106. Chen P, Nirula A, Heller B, Gottlieb RL, Boscia J, Morris J, et al. SARS-CoV-2 neutralizing antibody LYCoV555 in outpatients with Covid-19. N Engl J Med. 2021;384:229-37.

107. An EUA for bamlanivimab-a monoclonal antibody for COVID-19. JAMA. 2021;325:880.

108. Commissioner O of the. Coronavirus (COVID-19) Update: FDA Authorizes Monoclonal Antibodies for Treatment of COVID-19 [Internet]. FDA. FDA; 2020 [cited 2021 Mar 17]. Available from: https://www.fda. gov/news-events/press-announcements/coronaviruscovid-19-update-fda-authorizes-monoclonalantibodies-treatment-covid-19

109. Beigel JH, Tomashek KM, Dodd LE, Mehta AK, Zingman BS, Kalil AC, et al. Remdesivir for the treatment of Covid-19 - final report. N Engl J Med. 2020;383:1813-26.

110. van Paassen J, Vos JS, Hoekstra EM, Neumann KMI, Boot PC, Arbous SM. Corticosteroid use in COVID-19 patients: a systematic review and meta-analysis on clinical outcomes. Crit Care. 2020;24:696.

111. The RECOVERY Collaborative Group. Dexamethasone in hospitalized patients with Covid-19. N Engl J Med. 2021;384:693-704.

112. Kalil AC, Patterson TF, Mehta AK, Tomashek KM, Wolfe CR, Ghazaryan V, et al. Baricitinib plus remdesivir for hospitalized adults with Covid-19. N Engl J Med. 2021;384:795-807.

113. Honjo K, Russell RM, Li R, Liu W, Stoltz R, Tabengwa $\mathrm{EM}$, et al. Convalescent plasma-mediated resolution of COVID-19 in a patient with humoral immunodeficiency. Cell Rep Med. 2021;2:100164.

114. Hueso T, Pouderoux C, Péré H, Beaumont A-L, Raillon L-A, Ader F, et al. Convalescent plasma therapy for B-cell-depleted patients with protracted COVID-19. Blood. 2020;136:2290-5.

115. Taplitz RA, Kennedy EB, Bow EJ, Crews J, Gleason C, Hawley DK, et al. Outpatient management of fever and neutropenia in adults treated for malignancy: American Society of Clinical Oncology and Infectious Diseases Society of America Clinical Practice Guideline Update. J Clin Oncol. 2018;36:1443-53. 
116. Qin C, Zhou L, Hu Z, Zhang S, Yang S, Tao Y, et al. Dysregulation of immune response in patients with coronavirus 2019 (COVID-19) in Wuhan, China. Clin Infect Dis. 2020;71:762-8.

117. Taha M, Sharma A, Soubani A. Clinical deterioration during neutropenia recovery after G-CSF therapy in patient with COVID-19. Respir Med Case Rep. 2020;31:101231.

118. Nawar T, Morjaria S, Kaltsas A, Patel D, PerezJohnston R, Daniyan AF, et al. Granulocyte-colony stimulating factor in COVID-19: is it stimulating more than just the bone marrow? Am J Hematol. 2020;95:E210-3.

119. NCCN COVID-19 Vaccination Advisory Committee. Recommendations of the NCCN COVID-19 vaccination advisory committee. In: NCCN: Cancer and COVID-19 Vaccination. NCCN. 2021. https://www. nccn.org/covid-19/pdf/COVID-19_Vaccination_ Guidance_V2.0.pdf. Accessed 08 Apr 2021.

120. Sadoff J, Le Gars M, Shukarev G, Heerwegh D, Truyers $\mathrm{C}$, de Groot AM, et al. Interim results of a phase $1-2 \mathrm{a}$ trial of Ad26.COV2.S Covid-19 vaccine. N Engl J Med. 2021;384:1824-35.

121. Baden LR, El Sahly HM, Essink B, Kotloff K, Frey S, Novak R, et al. Efficacy and safety of the mRNA-1273 SARS-CoV-2 vaccine. N Engl J Med. 2021;384:40316.

122. Polack FP, Thomas SJ, Kitchin N, Absalon J, Gurtman A, Lockhart S, et al. Safety and efficacy of the BNT162b2 mRNA Covid-19 vaccine. N Engl J Med. 2020;383:2603-15.

123. Blanchette PS, Chung H, Pritchard KI, Earle CC, Campitelli MA, Buchan SA, et al. Influenza Vaccine effectiveness among patients with cancer: a population-based study using health administrative and laboratory testing data from Ontario, Canada. JCO. 2019;37:2795-804.
124. Ariza-Heredia EJ, Chemaly RF. Practical review of immunizations in adult patients with cancer. Hum Vaccin Immunother. 2015;11:2606-14.

125. Rubin LG, Levin MJ, Ljungman P, Davies EG, Avery R, Tomblyn M, et al. 2013 IDSA clinical practice guideline for vaccination of the immunocompromised host. Clin Infect Dis. 2014;58:e44-100.

126. Keam B, Kim M-K, Choi Y, Choi S-J, Choe PG, Lee K$\mathrm{H}$, et al. Optimal timing of influenza vaccination during 3-week cytotoxic chemotherapy cycles. Cancer. 2017;123:841-8.

127. Desai A, Gainor JF, Hegde A, Schram AM, Curigliano $\mathrm{G}$, Pal S, et al. COVID-19 vaccine guidance for patients with cancer participating in oncology clinical trials. Nat Rev Clin Oncol. 2021;18:313-9.

128. U.S. Department of Health and Human Services Food and Drug Administration. Conduct of clinical trials of medical products during the COVID-19 public health emergency. In: FDA Guidance Documents. FDA. 2021. https://www.fda.gov/regulatory-information/ search-fda-guidance-documents/fda-guidanceconduct-clinical-trials-medical-products-duringcovid-19-public-health-emergency. Accessed: $15 \mathrm{Mar}$ 2021.

129. van der Veldt AAM, Oosting SF, Dingemans A-MC, Fehrmann RSN, Geurtsvan Kessel C, Jalving M, et al. COVID-19 vaccination: the VOICE for patients with cancer. Nat Med. 2021;27:568-9.

\section{Publisher's note}

Springer Nature remains neutral with regard to jurisdictional claims in published maps and institutional affiliations. 